\section{Genetic and Phenotypic Parameter Estimates for Yield and Fruit Quality Traits from a Single Wide Cross in Yellow Passion Fruit}

\author{
Michel Choairy de Moraes, Isaias Olívio Geraldi, Frederico de Pina Matta, \\ and Maria Lucia Carneiro Vieira ${ }^{1}$ \\ Universidade de São Paulo, Escola Superior de Agricultura Luiz de Queiroz, \\ Departamento de Genética, P.O. Box 83, 13400-970 Piracicaba, Brazil
}

Additional index words. Passiflora, response to selection, genetic parameters, fruit yield

\begin{abstract}
The aim of this study was to estimate genetic and phenotypic parameters in a population of yellow passion fruit for determining its potential for genetic improvement, as well as to establish strategies for selection. The basic material comprises a sample of $100 \mathrm{~F}_{1}$ plants derived from a single cross between the accessions 'IAPAR-06' and 'IAPAR123', which are genetically divergent. The experimental evaluation was performed in a $10 \times 10$ triple lattice design. At harvest, yield and number of fruit were evaluated, as well as other traits related to fruit quality. Results indicated that the population displays wide genetic variability, with coefficients of heritability on a genotype mean basis varying from $52.6 \%$ to $83.2 \%$. High and positive genetic correlations were detected between yield and number of fruit and for combinations of the traits weight, length, and width of the fruit. Negative genetic correlations were found between the soluble solids content and the other traits. The relevance of the results from such a divergent cross to a commercial breeding program is discussed.
\end{abstract}

Passion fruit cultivation is a relatively recent activity in Brazil. It has been acquiring importance notably over the last 3 decades. Currently, it has earned the country an outstanding ranking on the world scene as the main producer. The commercial crops are based almost exclusively on a single species, Passiflora edulis f. flavicarpa, since it occupies $95 \%$ of all orchards. This species is planted in almost every Brazilian state, yielding a source of income for numerous localities, with a strong social appeal, since it is a labor-intensive crop. Despite its great importance, scientific research has not kept up with this expansion.

The wide genetic variability, both inter-and intraspecific, holds great potential to be exploited for genetic improvement, which could contribute substantially to increase yield and fruit quality as well as the resistance to major diseases. However, the use of such non-adapted material to improve a cultivar for one or more traits can be difficult because of the transfer of undesirable alleles together with the genes of interest. Moreover, studies on genetics of passion fruit and long-term breeding programs are only just beginning.

According to Meletti and Bruckner(2001), a cultivar developed for the fresh market should

Received for publication 7 July 2005. Accepted for publication 2 Sept. 2005. This project was financially supported by the Brazilian institutions FAPESP(grant no. 03/06074-4), CAPES (fellowship to F.P.M), and CNPq (fellowship to M.C.M.). The authors are grateful to R.J. Knight, Jr., and R.E. Litz, University of Florida, for reviewing the manuscript and Ricardo Vieira Cesar for his kind contribution in the proofreading of the text.

${ }^{1}$ To whom reprint requests should be addressed; e-mail mlcvieir@esalq.usp.br. display large oval-shaped fruit for a good commercial classification, good appearance, and resistance to transport and to the loss of quality during storage and commercialization. Alternatively, for the agro-industrial sector, the fruit should have a thin skin and a completely full cavity, high content of acid and soluble solids, and a uniform color.

The yellow passion fruit is an out-crossing plant for excellence. Cross-pollination is conditioned by the self-incompatibility, in which the pollen of one plant is unable to fertilize the flowers of the same plant, and different plants may or may not be compatible among them. There are evidences that this self-incompatibility is controlled by two loci, the sporophytic $S$ gene and a gametophytic gene that acts in association with the $S$ gene (Suassuna et al., 2003). Fertilization requires the presence of different cross-compatible genotypes and appropriate pollinating insects or manual pollination. In planning commercial orchards, one should keep in mind that the clones ought to possess sufficient diversity of alleles of selfincompatibility (Bruckner, 2002).

Several of the breeding methods available are useful for this species, but regardless of the method to be applied, the estimation of genetic and phenotypic parameters constitutes an important element of breeding programs, since it results in a better understanding of the genetic structure of the populations under study. In this sense, the partition of the phenotypic variances and covariances into its genetic and environmental components, the estimation of coefficients of heritability and of the associations among traits could provide a basis for planning a more efficient program.

This work is part of a major project whose objectives are studying several genetic features of $P$. edulis f. flavicarpa, including the construction of linkage maps and QTL mapping (Lopes et al., 2005; Matta, 2005, Vieira and Carneiro, 2004). In this particular study, we present estimates of genetic and phenotypic parameters of traits related to yield and fruit quality, such as genetic and phenotypic variances, coefficients of heritability, genetic correlations, and expected response to selection. Here we evaluated the same population used for mapping purposes; it derived from a single cross between two divergent accessions of the yellow passion fruit.

\section{Materials and Methods}

The passion fruit population resulted from a single cross between two plants of accessions from the germplasm collection of the Instituto Agronômico do Paraná (IAPAR). The female parent ('IAPAR-123') displays favorable agronomic characteristics with respect to total soluble solids, acidity, fruit yield and juice yield, since it resulted from a commercial selection. The male parent ('IAPAR-06') comes from Morocco and displays inferior agronomic characteristics. The choice of these parents was based on the phenotypic and molecular polymorphism that occurs between them, which guarantees the generation of a highly segregating $\mathrm{F}_{1}$ population (Carneiro et al., 2002).

A sample of 100 genotypes composed the base population, which was maintained in a greenhouse. Nine cuttings from each genotype were excised from the plants that were transferred to plastic cups containing a substrate for the root development. The rooted cuttings were then transferred to plastic pots for growth until their complete development. The experiment was installed in an experimental area of the Escola Superior de Agricultura "Luiz de Queiroz", Southeast of Brazil, at a longitude of $51^{\circ} 23^{\prime} 14^{\prime \prime W}$ and a latitude of $22^{\circ} 17^{\prime} 43^{\prime \prime S}$, during the first half of May 2002.

A triple $10 \times 10$ square lattice design was used. Plots were $15 \mathrm{~m}$ long, rows spaced 3 $\mathrm{m}$ apart, and plants spaced $5 \mathrm{~m}$ within rows, containing three plants tied and supported on wire trellises $1.9 \mathrm{~m}$ high. Supplementary irrigation and periodic pruning was carried out to stimulate new growth and for the individualization of the plants.

The following traits were evaluated: fruit yield per plant (FY) in $\mathrm{kg}$, number of fruit per plant (FN), average weight of the fruit (WE) in $\mathrm{g}$, average length (LE) and average width (WI) of the fruit in $\mathrm{cm}$, average percentage of pulp (PP), and average content of total soluble solids in Brix degrees (SS). The average percentage of pulp was calculated on a per weight basis, accordingly the formula: $P P=(W E-W B) /(W E)$ $\times 100$, where $W B$ refers to the weight of the fruit without the pulp.

The experimental data refers to the first harvest that ranged from January to July 2003. The weights and the number of fruit of the plots were evaluated weekly. Then the data were converted to plot means. For the other traits, evaluations were performed twice: once early in the harvest period (February) and again middle 
Table 1. Analysis of variance for fruit yield (FY) and number of fruit (NF) according to an incomplete lattice design.

\begin{tabular}{lrcc}
\hline Source of & & \multicolumn{2}{c}{ MS } \\
\cline { 3 - 4 } variation & df & \multicolumn{1}{c}{ FY } & $\mathrm{NF}^{\mathrm{z}}$ \\
\hline Replication (R) & 2 & $427.0^{* *}$ & $52.59^{* *}$ \\
Block/R & 27 & $35.3^{* *}$ & $3.98^{* *}$ \\
Genotype & 99 & $88.8^{* *}$ & $9.57^{* *}$ \\
Intrablock error & 164 & 17.5 & 1.79 \\
CV (\%) & & 23.8 & 11.8 \\
\hline
\end{tabular}

${ }^{\mathrm{z}}$ Square-root-transformed data.

${ }^{* *}$ Significant at $P \leq 0.01$.

Table 3. Means for fruit yield (FY), number of fruit (NF), average weight of fruit (WE), average length of fruit (LE), average width of fruit (WI), percentage of pulp (PP), and soluble solids content (SS).

\begin{tabular}{lccc}
\hline Trait & Period 1 & Period 2 & Mean \\
\hline FY (kg/plant) & --- & --- & 17.6 \\
NF (n $/$ plant) & --- & --- & 135.3 \\
WE (g/fruit) & 142.1 & 141.7 & 141.9 \\
LE (cm/fruit) & 8.13 & 7.97 & 8.06 \\
WI (cm/fruit) & 6.84 & 6.85 & 6.85 \\
PP (\%) & 42.6 & 47.0 & 44.7 \\
SS ( ${ }^{\circ}$ Brix) & 14.3 & 14.3 & 14.3 \\
\hline
\end{tabular}

to late in the period (May). Data of plot means for each period were considered for statistical analysis. These were obtained as the average of a fruit sample from the plots.

Plots were composed of three clones. To calculate the means, the sum of the observed values was divided by the number of plants even if one plant had died. However, if two plants died, the value obtained was treated as a result. Plots in which all clones died were treated as missing values.

The analyses of variance and covariance were performed with the computational program SAS Institute Inc., version 8, using the GLM (General Linear Models) procedure, and considering a random model, according to the following mathematical model for the traits averaged over the entire harvest period (fruit yield and fruit number): $\mathrm{Y}_{\mathrm{ijk}}=\mu+\mathrm{t}_{\mathrm{i}}+\mathrm{r}_{\mathrm{j}}$ $+b_{k(j)}+e_{i j k}$, where $Y_{i j k}=$ the observed value of the genotype $i$ in the block $k$ of the replication $j ; \mu=$ the overall mean; $t_{i}=$ the effect of the genotype $i ; r_{j}=$ the effect of the replication $j$; $b_{k(j)}=$ the effect of block $k$ within replication $j$; and $e_{i j k}=$ the error associated with $Y_{i j k}$ where $e_{i j k} \sim \mathrm{N}\left(0, \sigma^{2}\right)$.

For the traits evaluated in two periods (fruit traits) a split plot in time design was used and a random model, with the genotypes being the plots and the periods the subplots. A previous analysis was performed with plot means (two periods) to detect the efficiency of the lattice. Since a very low efficiency was detected for the intrablock control, it was decided to perform the analyses according to split plot in time in a randomized block design, according to the following model: $\mathrm{Y}_{\mathrm{ijk}}=\mathrm{i}+\mathrm{t}_{\mathrm{i}}+\mathrm{r}_{\mathrm{j}}+\mathrm{e}_{\mathrm{ij}}+\mathrm{s}_{\mathrm{k}}+$ $\mathrm{ts}_{\mathrm{ik}}+\mathrm{e}_{\mathrm{ijk}}$, where $Y_{i j k}$ is the observed value of genotype $i$ in the replication $j$ and in the period $k$; $\mu$ is the overall mean; $t_{i}$ is the effect of the genotype $i ; r_{j}$ is the effect of the replication $j$; $e_{i .}$ is the error among plots (error a); $s_{k}$ is the effect of the period $k ; t s_{i k}$ is the effect of the interaction between genotypes and periods; and $e_{i j k}$ is the error among subplots (error b).
Table 2. Analysis of variance for average weight of fruit (WE), average length of fruit (LE), average width of fruit (WI), percentage of pulp (PP), and soluble solids content (SS), according to a split plot in time model in a randomized block design.

\begin{tabular}{lrccccc}
\hline Source of & & \multicolumn{5}{l}{ MS } \\
\cline { 3 - 6 } variation & df & WE & LE & WI & PP & SS \\
\hline Replication & 2 & 702.7 & $1.139^{* * *}$ & $0.426^{* *}$ & 16.8 & 0.396 \\
Genotype (G) & 99 & $1,459.1^{* *}$ & $0.820^{* *}$ & $0.352^{* *}$ & $72.0^{* *}$ & $1.879^{* *}$ \\
Error (a) & 175 & 656.8 & 0.192 & 0.142 & 18.1 & 0.362 \\
Period (P) & 1 & 205.6 & $3.306^{* *}$ & 0.041 & $1,498.4^{* *}$ & 0.446 \\
G $\times$ P & 91 & 663.4 & 0.208 & $0.162^{*}$ & 26.2 & 0.401 \\
Error (b) & 122 & 588.2 & 0.191 & 0.115 & 27.5 & 0.299 \\
CV (\%) & & 17.1 & 5.4 & 4.9 & 11.7 & 3.8 \\
\hline
\end{tabular}

*,*** Significant at $P \leq 0.05$ or 0.01 , respectively.
From the mean squares of the analyses of variance, the components of variance were estimated. Then, the coefficients of heritability in the broad sense on a genotype (clone) mean basis were calculated, according to the following expressions: $h^{2}{ }_{m}=\left(\sigma_{G}^{2}\right) /\left[\sigma_{G}^{2}+\left(\sigma^{2} / R\right)\right]$ and $\mathrm{h}_{\mathrm{m}}^{2}=\left(\sigma_{\mathrm{G}}^{2}\right) /\left[\sigma_{\mathrm{G}}^{2}+\left(\sigma_{\mathrm{GP}}^{2} / \mathrm{P}\right)+\left(\sigma_{\mathrm{GR}}^{2} / \mathrm{R}\right)+\left(\sigma^{2} / \mathrm{RP}\right)\right]$, respectively, for the traits evaluated in one and two periods, where $\sigma_{\mathrm{G}}^{2}, \sigma_{\mathrm{GP}}^{2} \sigma_{\mathrm{GR}}^{2}$, and $\sigma^{2}$ refer to genetic variance, variance of the interaction between genotypes and periods, variance of the error among plots (error a) and variance of the error among subplots (error b), respectively; $\mathrm{R}$ represents the number of replications (i.e., 3) and $P$ the number of periods (i.e., 2).

The genetic coefficients of variation were calculated as $\mathrm{CV}_{\mathrm{G}}=\left(\sigma_{\mathrm{G}}^{2} \sqrt{\mathrm{X}}\right) 100$, where $\sigma^{2}{ }_{\mathrm{G}}$ is the genetic standard deviation and $\bar{X}$ is the population mean. The expected responses to selection of the best clones for a selection intensity of $20 \%$ were calculated as $\mathrm{Rs}=\overline{(\mathrm{X}}$ $\left.-\bar{X}_{\mathrm{o}}\right) \mathrm{h}_{\mathrm{m}}^{2}$, where $\overline{\mathrm{X}}_{\mathrm{s}}$ is the mean of the 20 best clones of the population, $\bar{X}_{0}$ is the original population mean, and $\mathrm{h}^{2}$ is the heritability coefficient on a genotype mean basis (Falconer and Mackay, 1996). The confidence intervals for the estimates of the variances and of the coefficients of heritability were obtained according to the methods reported by Knapp et al. (1985).

The analyses of covariance between the traits were similar to the analyses of variance. From the genetic and phenotypic variances and covariances, the genetic and phenotypic correlations involving all the traits were estimated following the procedure reported by Falconer and Mackay (1996): $\left.\mathrm{r}_{\mathrm{G}}=\left[\mathrm{COV}_{\mathrm{G}(\mathrm{x}, \mathrm{y}}\right)\right] /\left[\sigma_{\mathrm{G}(\mathrm{x})} \sigma_{\mathrm{G}(\mathrm{y})}\right]$ $=$ genetic correlation between traits $\mathrm{X}$ and $\mathrm{Y}$ and $\left.r_{\mathrm{F}}=\left[\mathrm{COV}_{\overline{\mathrm{F}}(\mathrm{x}, \mathrm{y}}\right)\right] /\left[\sigma_{\overline{\mathrm{F}}(\mathrm{x})} \sigma_{\overline{\mathrm{F}}(\mathrm{y})}\right]=$ phenotypic correlation between traits $\mathrm{X}$ and $\mathrm{Y}$ on a genotype mean basis.

Using the same procedure, genetic correlations between total yield and yield averaged in the first 2 and 3 months of the harvest were estimated.

\section{Results}

The analyses of variance for yield and number of fruit, both averaged in the entire harvest period are shown in Table 1. For number of fruit, phenotypic data did not display a normal distribution according to the Shapiro-Wilk test; thus, the analysis was performed with square root transformed data. Genotype effects were highly significant for the two traits, reflecting the wide genetic variability in the population. Replications and blocks within replications effects were also significant, showing the usefulness of the lattice design in isolating the sources of variation that could affect experimental accuracy for these two traits. The coefficient of experimental variation was higher for fruit yield, which is common in field experiments, and lower for number of fruit.

For the traits related to fruit quality (Table 2 ), the population also displays genetic variability as shown by the high significance of genotype effects. Interaction was detected between genotypes and periods only for the average width of the fruit, even though the soluble solids content showed significant
Table 4. Estimates of genetic variances $\left(\sigma_{\mathrm{G}}^{2}\right)$ and coefficients of heritability on a genotype mean basis $\left(\mathrm{h}_{\mathrm{m}}^{2} \%\right)$ with their respective confidence intervals $(\alpha=95 \%)$, coefficients of genetic variation $\left(\mathrm{CV}_{\mathrm{G}} \%\right)$ and expected response to selection (Rs\%) for fruit yield (FY), number of fruit (NF), average weight of fruit (WE), average length of fruit (LE), average width of fruit (WI), percentage of pulp (PP), and soluble solids content (SS).

\begin{tabular}{|c|c|c|c|c|}
\hline Trait & $\sigma_{G}^{2}$ & $\mathrm{~h}_{\mathrm{m}}^{2} \%$ & $\mathrm{CV}_{\mathrm{G}} \%$ & $\mathrm{Rs} \%$ \\
\hline$\overline{\mathrm{FY}}$ & $\begin{array}{c}26.8 \\
(19.4-39.5)\end{array}$ & $\begin{array}{c}82.2 \\
(72.4-85.6)\end{array}$ & 29.5 & 36.6 \\
\hline $\mathrm{NF}^{\mathrm{z}}$ & $\begin{array}{c}2.93 \\
(2.13-4.28)\end{array}$ & $\begin{array}{c}83.0 \\
(73.1-86.7)\end{array}$ & 15.0 & 35.9 \\
\hline WE & $\begin{array}{c}163.0 \\
(91.8-366.6)\end{array}$ & $\begin{array}{c}56.1 \\
(21.9-69.2)\end{array}$ & 9.00 & 10.7 \\
\hline LE & $\begin{array}{c}0.136 \\
(0.095-0.212)\end{array}$ & $\begin{array}{c}79.3 \\
(59.3-84.8)\end{array}$ & 4.58 & 5.71 \\
\hline WI & $\begin{array}{c}0.0368 \\
(0.020-0.085)\end{array}$ & $\begin{array}{c}52.6 \\
(19.0-65.6)\end{array}$ & 2.80 & 2.92 \\
\hline PP & $\begin{array}{c}12.16 \\
(8.37-19.29)\end{array}$ & $\begin{array}{c}83.2 \\
(55.7-88.6)\end{array}$ & 7.80 & 10.1 \\
\hline $\mathrm{SS}$ & $\begin{array}{c}0.316 \\
(0.223-0.484)\end{array}$ & $\begin{array}{c}79.0 \\
(62.6-84.3)\end{array}$ & 3.93 & 4.91 \\
\hline
\end{tabular}

${ }^{\mathrm{z}}$ Square-root-transformed data. 
Table 5. Estimates of coefficients of genetic correlation (above the diagonal) and phenotypic correlation on a genotype mean basis (below the diagonal) between fruit yield (FY), number of fruit (NF), average weight of fruit (WE), average length of fruit (LE), average width of fruit (WI), percentage of pulp (PP), and soluble solids content (SS)

\begin{tabular}{lcrrrrrr}
\hline & FY & NF & \multicolumn{1}{c}{ WE } & LE & \multicolumn{1}{c}{ WI } & \multicolumn{1}{c}{ PP } & SS \\
\hline FY & & 0.865 & 0.357 & 0.394 & 0.323 & 0.129 & -0.358 \\
NF & 0.889 & & -0.101 & 0.091 & -0.084 & 0.138 & -0.173 \\
WE & 0.297 & -0.001 & & 0.632 & 0.779 & -0.042 & -0.561 \\
LE & 0.348 & 0.119 & 0.712 & & 0.663 & 0.127 & -0.291 \\
WI & 0.262 & -0.011 & 0.834 & 0.694 & & -0.159 & -0.508 \\
PP & 0.152 & 0.155 & 0.205 & 0.219 & 0.077 & & -0.088 \\
SS & -0.267 & -0.126 & -0.268 & -0.177 & -0.244 & -0.003 & \\
\hline
\end{tabular}

interaction at $P \leq 0.10$. The coefficients of experimental variation were low for these traits except for average weight of the fruit. Statistical difference $(P \leq 0.01)$ between periods was detected only for average length of the fruit and percentage of pulp. The trait means are shown in Table 3.

Estimates of genetic variances, coefficients of heritability, coefficients of genetic variation and expected response to selection for all of the traits are shown in Table 4. Fruit yield, number of fruit, average length of fruit, percentage of pulp and soluble solids content showed the greatest coefficients of heritability. The smallest value was found for the width of the fruit, but in general, all of these coefficients are considered high. The expected response to selection based on the $20 \%$ best clones varied according to the trait, being greater for yield and number of fruit, which reflects their greater variability, as may be seen by the coefficients of genetic variation. For the traits related to fruit quality the expected response to selection were smaller, because of the smaller coefficients of genetic variation.

The estimates of coefficients of genetic correlation as well as phenotypic correlation on a genotype mean basis are shown in Table 5 . Note the high genetic correlation between yield and number of fruit, being both traits indicative of the yield potential of the plants. The total soluble solids content showed a negative correlation with all of the other traits, which indicates that the selection for increasing yield would result in a reduction in the soluble solids content. The percentage of pulp showed a low correlation with all of the other traits while the average weight of the fruit is highly correlated with the length and the width of the fruit, as expected. Note also a high agreement between the coefficients of genetic and phenotypic correlation. Remarkable, the yield in the first 3 months of harvest was highly correlated with total yield $(r=0.95)$. Taking into consideration the yield in the first 2 months, this value was smaller $(r=0.76)$.

\section{Discussion}

The literature reports a large variability existing in Brazilian populations of yellow passion fruit for yield potential as well as for fruit characteristics (for a review, see Vieira and Carneiro, 2004). In this study, the analyses of variance indicated that the $F_{1}$ population displays a wide genetic variability for all of the traits evaluated; this was expected due to the genetic divergence of the parents that are supposed to accumulate high levels of het- erozygous loci because of the genetic nature of the species. Thus, the high coefficients of heritability for most of the traits and the high coefficients of genetic variation for some of them (mainly for FY and NF) point to good prospects for the selection of superior genotypes, seeking to take advantage of the favorable alleles present in the parents.

Considering the spacing adopted between plants, the population mean was $11.34 \mathrm{t} \cdot \mathrm{ha}^{-1}$, which is low. However, this value was already expected because the male parent ('IAPAR06') was known to be inferior for the traits related to yield. In fact, this parent yielded $8.93 \mathrm{t} \cdot \mathrm{ha}^{-1}$ on average. The individual values for yield ranged, on average, from 2.39 to $21.31 \mathrm{t} \cdot \mathrm{ha}^{-1}$.

The traits related to fruit quality were evaluated during two distinct periods of the same harvest, making possible the analysis of the interaction between genotypes and periods. A significant interaction was detected only for fruit width and soluble solids content. The lack of interaction for the other traits indicate that with a single evaluation during the harvest period for traits related to fruit quality would be possible to identify and select the superior genotypes. Nevertheless, with a greater number of evaluations (periods), this consistency would not necessarily occur. Maluf et al. (1989) reported a considerable interaction between genotype and sampling periods for soluble solids content, and to a lesser degree, for percentage of pulp, as shown by the low genetic correlation of the traits in two sampling periods. Besides, in the present work only for average length of the fruit and percentage of pulp, the means were significantly different for the two periods.

The selection for yield should also influence positively the number of fruit due to their high genetic correlation. With relation to the yield potential of the plants, the number of fruit as well as the yield should be used as indicators. However, it is preferable to select the most productive plants by the yield, because in this way the indirect selection of the plants takes place with the heaviest fruit, since these two traits have a positive correlation. Bruckner (2002) emphasized the difficulty of evaluating the total yield of the passion fruit, because it tion of this trait requires constant evaluations. One way of indirectly evaluating the total yield is to collect information at the beginning of the harvest. In this study, the yield in the first three months of harvest did perform as an excellent indicator of the yield potential of the plants. Due to the difficulty of evaluating extends over a long period. Indeed, the evalua- a longer period, still the yield in the first two months should be useful. On the other hand, Maluf et al. (1989) obtained a lower genetic correlation $(r=0.52)$ between total yield and the yield of the first 10 weeks of harvest. In fact, more studies are necessary with respect to the correlation between initial yield and total yield to achieve the maximum gain per cycle in a lesser time and in a lower cost. In this sense, the information of this paper could assist breeding programs.

The negative correlation between soluble solids content and other traits is an important issue to be considered. It means that the values of the yield decreases, for example, under selection for soluble solids content. This would be more serious in selection programs for the industry, were greater soluble solids contents is desirable. Viana et al. (2003) also found negative genetic correlations between soluble solids content and number of fruit, length and width of fruit, thickness of skin and weight of fruit. In such situations, it is often necessary to use the selection indices for improving one trait without changing the average of another trait in an undesirable direction (Bernardo, 2002; Falconer and Mackay, 1996).

Crossing between two divergent parents was done to maximize the genetic variability and heterozygosity within the population. The relevance of the results from such a wide cross is that they should be directly applicated to commercial breeding programs. The best plants of the population could be selected and cloned by cuttings, generating an improved population, which could be used directly for multiplication and distribution to the producers. At the same time, those clones could be recombined by intercrossing the plants for increasing the frequency of favorable alleles.

We suggest a long-term program for passion fruit breeding based on recurrent selection. We are aware of the necessity of conducting additional crosses and studies to estimate the correlation between parents and progenies as well as narrow-sense heritability coefficients to support this investigation. Furthermore, the selection intensity cannot be very high to maintain enough genetic divergence for the $\mathrm{S}$ incompatibility alleles of $P$. edulis. Otherwise, it would result in losses during commercial production. In this work, an empirical selection of the 20 best clones for fruit yield was simulated (selection intensity of $20 \%$ ) based on the premise that they will produce pollen with sufficient variability for the alleles affecting compatibility. However, it is necessary to carry out specific studies to evaluate the minimum number of genotypes of a population, which would result in an adequate pollination and consequently guarantee that the yield potential of a genotype be expressed.

The development of a breeding population was used in apple as a strategy to integrate the use of a wide genetic diversity with application of quantitative genetic principles through recurrent selection (Noiton and Shelbourne, 1992). As in apple, the results here provided could serve as a basis for breeding programs of yellow passion fruit to obtain plants that are more productive, and with improved fruit quality. 


\section{Literature Cited}

Bernardo, R. 2002. Breeding for quantitative traits in plants. Stemma Press, Woodbury, Minn.

Bruckner, C.H. 2002. Melhoramento de fruteiras tropicais. 1st ed. Viçosa Fed. Univ. Press, Vicosa, Brazil.

Carneiro, M.S., L.E.A. Camargo, A.S.G. Coelho, R. Vencovsky, R.P. Leite, N.M.C. Stenzel, and M.L.C. Vieira. 2002. RAPD-based genetic linkage maps of yellow passion fruit (Passiflora edulis Sims f. flavicarpa Deg.). Genome 45:670-678.

Falconer, D.S. and T.F.C. Mackay. 1996. Introduction to quantitative genetics. 4th ed. Longman, New York.

Knapp, S.J., W.W. Stroup, and W.M. Ross. 1985 Exact confidence intervals for heritability on a progeny mean basis. Crop Sci. 25:192-194.
Lopes, R., M.T.G. Lopes, M.S. Carneiro, F.P. Matta L.E.A. Camargo, and M.L.C. Vieira, M.L.C. 2005. Linkage and mapping of resistance genes to Xanthomonas axonopodis pv. passiflorae in yellow passion fruit. Genome (in press).

Maluf, W.R., J.R. Silva, D. Grattapaglia, M. TomaBraghini, R.D. Corte, M.A. Machado, and L.S. Caldas. 1989. Genetic gains via clonal selection in passion fruit Passiflora edulis Sims. Braz. J Genet. 12:833-841.

Matta, F.P. 2005. Mapeamento de QRL para Xanthomonas axonopodis pv. passiflorae em maracujá-amarelo (Passiflora edulis Sims f. flavicarpa Deg.). $\mathrm{PhD}$ thesis. Universidade de São Paulo, Piracicaba.

Meletti, L.M.M. and C.H. Bruckner. 2001. Melhoramento genético, p. 345-385. In: C.H. Bruckner and M.C. Picanço (eds.). Melhoramento de fruteiras tropicais. Cinco Continentes, Porto
Alegre, Brazil.

Noiton, D. and C.J.A. Shelbourne. 1992. Quantitative genetics in an apple breeding strategy. Euphytica 60: 213-219.

Suassuna, T.M.F., C.H. Bruckner, C.R. Carvalho, and A. Borém. 2003. Self-incompatibility in passionfruit: evidence of gametophytic-sporophytic control. Theor. Appl. Genet. 106:298-302.

Viana, A.P., T.N.S. Pereira, M.G. Pereira, M.M Souza, J.F.M. Maldonado, and A.T. Amaral, Jr. 2003. Simple and canonic correlation between agronomical and fruit quality traits in yellow passion fruit (Passiflora edulis f. flavicarpa) populations. Crop Breed. Appl. Biotechnol. 3:133-140.

Vieira, M.L.C., and M.S. Carneiro. 2004. Passiflora spp. Passion fruit, p. 435-453. In: R.E. Litz(ed.). Biotechnology of fruit and nut crops. CAB Intl. Publ., Oxfordshire, U.K. 